\title{
The Use of the Gene Xpert Mycobacterium tuberculosis/Rifampicin (MTB/Rif) Assay in Detection of Multi-Drug Resistant Tuberculosis (MDRTB) in Nnamdi Azikiwe University Teaching Hospital, Nnewi, Nigeria
}

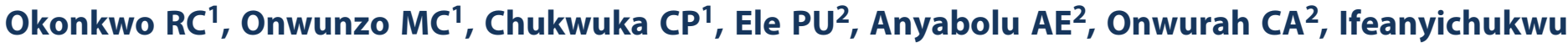 \\ $\mathrm{MO}^{3}$, Akujobi $\mathrm{CN}^{1}$, Enemuo $\mathrm{E}^{2}$ and Ochei $\mathrm{KC}^{4}$
}

\author{
${ }^{1}$ Department of Medical Microbiology/Tuberculosis, Nnamdi Azikiwe University Teaching Hospital, Nnewi, Nigeria \\ ${ }^{2}$ Department of Internal Medicine, Nnamdi Azikiwe University Teaching Hospital, Nnewi, Nigeria \\ ${ }^{3}$ Department of Immunology, College of Health Sciences, Nnamdi Azikiwe University, Nnewi Campus, Nigeria \\ ${ }^{4}$ Family Health International, Abuja, Nigeria
}

Corresponding author: Ifeanyichukwu MO, Department of Immunology, College of Health Sciences, Nnamdi Azikiwe University, Nnewi Campus, Nigeria, Tel: 2348037200407; E-mail: moifeanyi@yahoo.co.uk

Received date: December 15, 2016; Accepted date: December 25, 2016; Published date: December 31, 2016

Citation: Okonkwo RC, Onwunzo MC, Chukwuka CP, et al. The Use of the Gene Xpert Mycobacterium tuberculosis/Rifampicin (MTB/Rif) Assay in Detection of Multi-Drug Resistant Tuberculosis (MDRTB) in Nnamdi Azikiwe University Teaching Hospital, Nnewi, Nigeria. J HIV Retrovirus. 2017, 3:1.

Copyright: (C) 2017 Okonkwo RC, et al. This is an open-access article distributed under the terms of the Creative Commons Attribution License, which permits unrestricted use, distribution, and reproduction in any medium, provided the original author and source are credited.

\section{Abstract}

Tuberculosis (TB) remains a major public health problem in the developing world, partly due to a steady increase in the frequency of Mycobacteria tuberculosis strains becoming resistant to one or more of the first line anti-TB drugs. Microscopy is the most available diagnostic technique but the method cannot test for drug resistance. Culture method is the gold standard important in diagnosis and drug resistance testing, but it has the problem of prolonged turnaround time, high costs and unavailability. The Gene Xpert method for XpertMTB/Rif assay, allows rapid diagnosis of tuberculosis/multiple drug resistance Mycobacterium tuberculosis (MTB/MDRTB). The aim of this study is to evaluate the performance of the XpertMTB/Rif assay method in the diagnosis of MTB and drug resistance tuberculosis (DR-MTB) within one year of its installation in Nnamdi Azikiwe University Teaching Hospital, Nnewi, Nigeria. Sputum samples from 586 patients who presented at the DOTS laboratory of the hospital between $17^{\text {th }}$ June 2014 and $17^{\text {th }}$ June 2015 were processed using the XpertMTB/Rif assay machine. One hundred and sixteen (116) (19.8\%) of the 586 screened patients had MTB positive results, $8(6.9 \%)$ of the 116 MTB positive patients had rifampicin resistant TB. Also total of 336 out of whole total of 586 patients had HIV positive and $42(12.5 \%)$ of 336 HIV positive patients had MTB positive results. These depict the usefulness of Xpert assay method in MTB/MDRTB diagnosis.

Keywords Mycobacteria tuberculosis; Drug resistance; Health interventions

\section{Background}

Tuberculosis (TB) remains a major public health problem in the developing world, a situation worsened by the emergence of HIV/AIDS and multidrug resistant tuberculosis (MDRTB) strains [1]. MDR-MTB is defined as resistance to Isoniazed and Rifampicin, with or without resistance to other frontline drugs. According to the World Health Organization (WHO) global TB report of 2015, Nigeria is one of the six countries that stand out as having the largest number of incident cases of TB in 2014 with India and Nigeria accounting for one-third of global TB deaths [2]. TB has non-specific clinical features; hence its diagnosis requires laboratory testing that is accurate. Accurate and rapid diagnosis is essential for more effective public health interventions, earlier treatment initiation and better treatment outcomes [3].

Sputum smear microscopy is the only accessible technique in most facilities in the developing world. The technique is inexpensive requiring no complicated equipment and can diagnose the most infectious patients with relatively high specific results that always prompt treatment without further confirmations [4].

However, microscopy has a variably low sensitivity especially in children and HIV/AIDS patients. It detects fewer than $60 \%$ of all new TB infections and as few as $20 \%$ to $35 \%$ of HIV/TB infections [5]. High prevalence of TB is associated with a steady increase in the frequency of $M$. tuberculosis strains becoming resistant to the first line anti-TB drugs. Microscopy method cannot test for drug resistance, but patients with MDR TB require prompt second line treatment to prevent morbidity or mortality and the creation of a continuous pool of MDR TB in the communities [6]. 
Culture is the gold standard method and drug sensitivity testing (DST) can be done but it is costly and therefore unavailable in most sites. There is also the risk of contamination and prolonged turnaround time due to the slow growth rate of the TB bacilli [7]. Available newer and faster methods like MODS (Microscopic Observation Drug Susceptibility Assay), MGIT (Mycobacterium tuberculosis Growth Indicator Tube) and colorimetric assay all require specialized skills and bio-safety laboratories that are often unavailable in the regions where these methods are mostly needed [8].

The gene Xpert machine (XpertMTB/RIF Assay method) has the potential to revolutionize the diagnosis of TB based on its speed, sensitivity and specificity [9]. It is a cartridge-based automated diagnostic test that can, in less than $2 \mathrm{~h}$, simultaneously detects Mycobacterium tuberculosis organisms as well as rifampicin resistance by using three specific primers and five unique molecular probes which ensure a high degree of specificity. The use of sealed and disposable cartridges apparently overcomes the problem of cross contamination. There is minimal bio-hazard so that bio-safety cabinets are not compulsorily needed. The Xpert MDR/Rif assay method which is a nucleic acid amplification test (NAAT) based on the principle of polymerase chain reaction (PCR) has opened a new era of widespread molecular diagnosis of TB. Its hands-on operation is easy and requires minimal technical expertise [10].

It was developed by the laboratory of Professor David All of the University of Medicine and Dentistry of New Jersey together with Cepheid incorporation and FIND (Foundation of Innovative New Diagnostics) with additional financial support from the United States National Institute of Health (NIH), Bill and Melinda Gates Foundation [11]. The gene Xpert system was launched in 2004 while the first clinical validation studies were carried out in 2009 in some countries including South Africa and India, after which the machine was endorsed by WHO in 2010 for use in TB endemic countries [12].

With technical assistances of WHO, KNCVT Tuberculosis Foundation (TBCARE 1 Consortium) and international partners including Family Health international (FHI) 360 and Institute of Human Virology, Nigeria (IHVN), the National TB and Leprosy control Programme (NTBLCP) has been able to install the machine in a number of facilities across Nigeria [10]. The machine was installed in Nnamdi Azikiwe University Teaching Hospital, (NAUTH) Nnewi in 17th June 2014 and has uninterruptedly been in use since then.

The aim of this study was to evaluate the performance of the Xpert/RIF assay method for the diagnosis of TB and DR-TB within the one year of its installation in NAUTH, Nnewi.

\section{Methodology}

The study population comprised of 586 patients who presented at the DOTS laboratory, NAUTH, Nnewi between 17th June 2014 and $17^{\text {th }}$ June 2015. The categories of patients included presumptive DR-TB cases, presumptive TB cases of people living with HIV, cases of treatment defaults and failures and relapse TB cases. Before samples were collected from the patients' Ethical approval was sort and obtained from Ethics
Committee of Nnamdi Azikiwe University Teaching Hospital Nnewi, Nigeria. Informed consent was also obtained from the patients. One sample of sputum was collected from each of the patients in leak proof, screw cap and wide mouthed sputum cups. Patients were instructed on the right kind and volume of sputum to be collected. Sputum specimens were routinely processed as they came. Sputum specimens were diluted 1.2 $(\mathrm{v} / \mathrm{v})$ with buffer, mixed vigorously and incubated at room temperature with intermittent shaking at 10 minutes for complete liquefaction.

Two (2.0) $\mathrm{ml}$ aliquots of each diluted specimen were dispensed into the cartridge port and loaded accordingly into the Xpert machine for automated processing which included ultrasonic lysis of the mycobacterium to release DNA, washing and filtration, amplification and quantification of the DNA by real time PCR as well as detection of mutations on the rpoB gene using molecular beacons, with display of result within $2 \mathrm{~h}$.

\section{Results}

The study population comprised of 586 patients, 313 males (53.4\%) and 273 females (46.6\%). Of these 586 patients 336 were HIV positive, 220 were HIV negative while 30 had unknown HIV status. Further categorization of the patients based on the reasons for doing the test showed that most of patients were HIV positive cases 316 (53.9\%) while defaulter cases had the lowest occurrence 19 (3.2\%), relapse cases were 31 (5.3\%), MDRTB contacts were 30 (5.1\%) and MDRTB suspects were 119 (20.3\%), while treatment failures were $71(12.1 \%)$ as shown in Table 1.

Table 1 The patient's gender, HIV status and reason for testing represented in percentage.

\begin{tabular}{|c|c|}
\hline Patients characteristics & No of Patients \\
\hline Total no of patients & 586 \\
\hline No of males & $313(53.4 \%)$ \\
\hline No of females & $273(46.6 \%)$ \\
\hline \multicolumn{2}{|l|}{ HIV Status } \\
\hline Total no of patients & 586 \\
\hline No of HIV-positive patients & $336(57.3 \%)$ \\
\hline No of HIV negative patients & $220(37.5 \%)$ \\
\hline No of HIV unknown patients & $30(5.1 \%)$ \\
\hline \multicolumn{2}{|l|}{ Reasons for test } \\
\hline Total no of patients & 586 \\
\hline Treatment failures & $71(12.1 \%)$ \\
\hline Defaults & $19(3.2 \%)$ \\
\hline Relapse & $31(5.3 \%)$ \\
\hline TB contacts & $30(5.1 \%)$ \\
\hline HIV positive & $316(53.9 \%)$ \\
\hline
\end{tabular}


The performance of the xpert/MTB Rif assay method among the study population is as shown in Table 2; $116 \%$ of the 586 patients had MTB positive results while $470 \%$ had MTB negative results. A total of $8(6.9 \%)$ of the 116 MTB positive patients had rifampicin resistant TB. Rifampicin resistance was not detected in 97 of the 116 MTB positive cases while 11 had rifampicin resistance indeterminate results.

Table 2 Detection of MTB/Rif resistance using Xpert MTB/Rif assay.

\begin{tabular}{|l|l|}
\hline Xpert characteristics & Frequency (\%) \\
\hline MTB detection in the 586 patients & \\
\hline MTB detected & $116(19.8 \%)$ \\
\hline MTB not detected & $470(80.2 \%)$ \\
\hline Rifampicin resistance detection $(n=116)$ & $8(6.9 \%)$ \\
\hline Rifampicin detected & $97(83.6 \%)$ \\
\hline Rifampicin not detected & $11(9.5 \%)$ \\
\hline Indeterminate resistance & \\
\hline
\end{tabular}

Table 3 shows the MTB detection by the Xpert assay method in relation to patients HIV status. MTB was detected in 37 of 316 HIV positive cases. Of these 42 MTB positive patients 2 had rifampicin resistant TB while 6 of the 220 HIV negative patients had rifampicin resistance and none of the 30 patients with unknown HIV status had rifampicin resistant TB.

Table 3 MTB detection by Xpert.

\begin{tabular}{|l|c|c|c|c|}
\hline HIV status & $\begin{array}{c}\text { Rif } \\
\text { resistance }\end{array}$ & $\begin{array}{c}\text { No Rif } \\
\text { resistance }\end{array}$ & $\begin{array}{c}\text { Rif } \\
\text { indeterminate }\end{array}$ & Total \\
\hline Positive & - & - & - & - \\
\hline Negative & 6 & 54 & 8 & 68 \\
\hline Positive & 2 & 37 & 3 & 42 \\
\hline Unknown & 0 & 6 & 0 & 6 \\
\hline Total & 8 & 97 & 11 & 116 \\
\hline
\end{tabular}

\section{Discussion}

Rapid detection of TB/MDRTB is critical for improving patients care and decreasing TB transmission. The second line drugs for treatment of MDRTB are more expensive, not commonly available, have more adverse side effects and with extended treatment duration [13]. The prolonged duration of treatment may further compound issues in view of the socio-economic impact on the patient and his immediate family. So the importance of early detection of TB and Rifampicin strain cannot be over emphasized.

The MTB/RIF assay method is a good and reliable proxy for MDRTB and enables earlier initiation of treatment and better treatment outcome which are essential in decreasing MDRTB transmission [11].

In this present study 8 (6.9\%) of the 116 MBT positive cases detected had rifampicin resistant TB and had been enrolled for appropriate interventions. All were retreatment cases, 6 treatment failures, 1 relapse and 1 return after default. Continued treatment in the standard manner for them might have been waste of time and the drugs. They would have remained in their various communities probably with each of them infecting between 10-15 more people with MDRTB within one year period. A previous study in Nnewi showed that the proportion of TB cases with resistance to single drugs ranged from $2.7 \%$ for rifampicin to $6.6 \%$ for isoniazid [14].

Upto 42 (12.5\%) of 316 HIV positive patients had MTB positive results. That was a good proportion considering the paucibacillary nature of TB in HIV infected people. These depict the usefulness of Xpert in TB/MDRTB diagnosis. Two (25\%) of 8 rifampicin resistant TB patients were HIV positive patients while 6 (75\%) were HIV negative patients. HIV status may have no link with development of rifampicin resistance in the study population.

MDRTB cases have been reported from various studies across Nigeria. The MDRTB prevalence rate of $6.9 \%$ found in this study is comparable with $4.0 \%$ rate reported in Calabar [13] and $5.8 \%$ recorded among TB patients in Abeokuta [15]. A study in Kwara in 2013 by Rasaki et al. recorded a prevalence of Rifampicin mono-resistance using GeneXpert to be $7.2 \%$ [16].

The $6.9 \%$ prevalence rate seen in this study is quite lower than $30 \%$ prevalence rate reported in Ibadan and in two separate studies at Lagos, $18.5 \%$ by Nwokoye et al. and $23.0 \%$ by Enya et al. [17-19]. A study by Lawson et al. using BACTEC MGIT showed rifampicin resistance of $19 \%$ [20]. Other studies by Nwadioha et al. and by Bello et al. using GeneXpert reported average prevalences of $13.9 \%$ and $18.8 \%$ respectively $[21,22]$.

Differences in prevalence rates could be due to different test methods employed for the different studies. Again, the extent and burden of MDRTB vary significantly from country to country and from region to region [23]. Treatment practices and implementation of control programmes could be issues also [24].

The age groups 21-30 to 41-50 which constitute the productive and reproductive age groups were the most affected while the sex distribution showed a male preponderance as shown in Figures $\mathbf{1}$ and $\mathbf{2}$ respectively. The gender difference is probably due to difference in risk, the associated habits of alcoholism and smoking among the males which may imply an increased susceptibility of the males to respiratory illness. The males who are also the bread winners in this locality are mostly traders and trading here is done in crowded environment which constitutes a risk factor for TB acquisition. 
Age of tuberculosis patients $(n=116)$

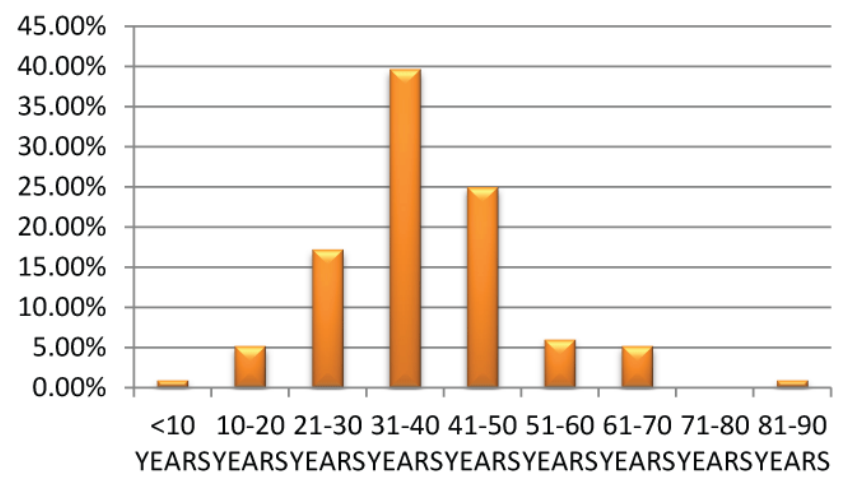

Figure 1 Age distribution of MTB positive patients.

The Sexes Of The Patients With TB $(\mathrm{N}=116)$

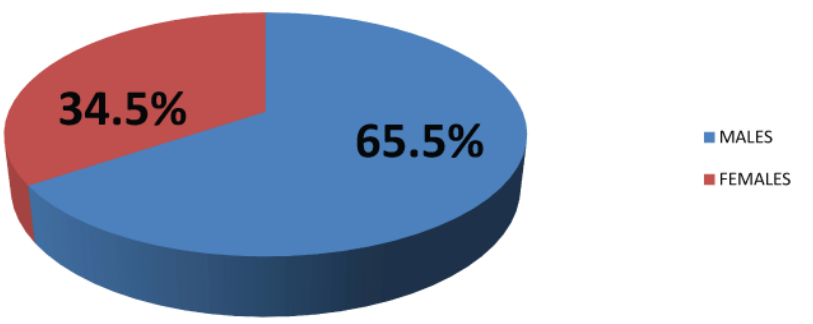

Figure 2 Sex distribution of patients with MTB positive results.

\section{Conclusion}

Xpert gene assay methods in TB/MDRTB diagnosis in our facility reveal high positive TB and Rifampicin resistance.

\section{Recommendation}

The WHO estimates that the prevalence of MDRTB in Nigeria is about $2.2 \%$ among new cases and $9.4 \%$ among retreatment cases, ranking the country the 15th among the 27 high burden MDRTB countries [25]. Despite this high prevalence, facilities for diagnosis of MDRTB are limited and treatment largely unavailable. Some concerns have been raised about the operational issues and limitations of the gene xpert machine due to its cost. There is need to strengthen the health system and increase capacity. Gene Xpert machine should be made available in all centers to ensure the rapid diagnosis of tuberculosis and rifampicin resistance therefore curbing the prevalence of MDRTB in our country. 


\section{References}

1. World Health Organization (2011) Address TB/HIV, MDRTB/XRTB and other challenges. Global tuberculosis control report.

2. World Health Organization (2015) World health organization global tuberculosis report.

3. Soini H, Musser JM (2001) Molecular diagnosis of mycobacteria. Clinical chemistry 47: 5809-5814.

4. Mark DP, Giorgio R, Alimuddin Z (2006) Progress towards improved tuberculosis diagnostics for developing countries. Lancet 367: 942-943.

5. Steingart KR, Megan H, Virenne NG (2009) Sputum processing method to improve the sensitivity of smear microscopy for tuberculosis: A systematic review. The Lancet Infect Dis 6: 664-677.

6. Boehme CC, Hillemann DN, Nicol MP, Shenai S (2010) Rapid molecular detection of tuberculosis and rifampicin. Eng J Med 363: 1005.

7. Cuevas LE, Vassin MA, Al-Sonboli, Lawson N, BAhader J (2011) A multi-country non-inferioriy cluster randomize trial of frontloaded smear microscopy for the diagnosis of pulmonary tuberculosis. PLOS Med 8: 1000403.

8. Hooja S, Pal N, Malhotra B, Goyal S, Kumar V (2011) Comparison of Ziehl- Neelsen and Auramine staining methods on direct and concentrated.

9. Carlton AA (2011) Gene Xpert: Agame changer for tuberculosis control? PLOS Medicine.

10. World Health Organisation (2012) WHO Nigeria supports introduction of Xpert MTB/RIF technology for diagnosis of MDRTB in Nigeria.

11. Papaventsis D, loannidis P, Evangelos V (2014) Tuberculosis diagnosis update: the new gene xpert MTB /RIF assay. Hellenic centre for disease control and prevention. E-bulletin.

12. World Health Organisation (2010) WHO endorses new rapid tuberculosis test.

13. Otu A, Umoh V, Habib A, Ameh S, Lawson L, et al. (2013) Drug resistance among pulmonary tuberculosis patients in Calabar, Nigeria. Pulmonary Medicine.

14. Uzoewulu NG, Ibe IN, Lawson L, Goyal M, Umenyona N, et al. (2014) Drug resistant Mycobacterium tuberculosis in tertiary hospital, South East, Nigeria. J Med Microb Diagn 3: 141.
15. Oluwaseun E, Akaniyi AP, Onabanjo O (2013) Primary multi drug resistant tuberculosis among HIV seropositive and seronegative patients in Abeokuta, Southwest Nigeria. American Journal of Research Communication 1: 224-225.

16. Rasaki SO, Ajibola AA, Musa SA, Moradeyo AK, Odeigah LO, et al. (2014) Rifampicin resistant tuberculosis in a secondary health institution in Nigeria, West Africa. J Infect Dis Ther 2: 139.

17. Kekinde AO, Adebiyi EO (2013) Molecular diagnosis of MDRTB using genotype MTBDR plus 96 assays in Ibadan, Nigeria. J Physiol Sci 28: 187-191.

18. Nwokoye NN, Onubogu CC, Nwadike PO, Abiodun AT, Tochukwu $\mathrm{NE}$, et al. (2014) Performance and biosafety implications of Genexpert MTB/RIF assay. International Journal of Microbial and Epidemiological Research 2: 19-27.

19. Enya VNV, Onubuogu C, Wahab MO, Efere LO, Motayo BO, et al. (2015) Prevalence of MDR-TB amongst patients with HIV and TB coinfection seen at the DOTs clinic of Nigeria Institute of Medical Research (NIMR). 6th IAS conference on HIV pathogenesis and treatment, Lagos, Nigeria.

20. Lawson L, Habib AG, Okobi MI, Idiong D, Olajide I, et al. (2010) Pilot study on multi drug resistant tuberculosis in Nigeria. Annals of African Medicine 9: 184-187.

21. Nwadioha SI, Nwokedi EO, Ezema GC, Eronini SC, Anikwe A, et al. (2014) Drug resistant Mycobacterium tuberculosis in Benue, Nigeria. Br Microbiol Res J 4: 988-995.

22. Bello LA, Shittu MO, Shittu BT, Oluremi AS, Akinnuroju ON, et al. (2014) Rifampicin mono-resistant mycobacterium tuberculosis among patients visiting the chest clinic, state specialist hospital, Akure, Nigeria. International Journal of Respiratory Medical Science 2: 1134-1137.

23. Ormerod $P$ (2005) Multi Drug Resistant Tuberculosis (MDRTB): Epidemiology, prevention and treatment. Br Med Bull 74: 17-24.

24. Caminero JA (2010) Multi drug resistant tuberculosis: Epidemiology, risk factors and case finding. Int J Tuberc Lung Dis 14: 382-390.

25. World Health Organisation (2011) Global Tuberculosis. WHO, Geneva, Switzerland. 